\title{
Assistive Technology-based Programs for Promoting Independence of Post-coma Children
}

\author{
Fabrizio Stasolla ${ }^{1^{*}}$, Adele Boccasini ${ }^{2}$, Annalisa Albano ${ }^{3}$ and Vincenza Albano ${ }^{3}$ \\ ${ }^{1}$ Department of Neurosciences, University of Bari, Italy \\ ${ }^{2}$ Lega del Filo d'Oro Research Center, Termini Imerese, Italy \\ ${ }^{3}$ Department of Educational Sciences, Psychology, Communication, University of Bari, Italy \\ *Corresponding author: Stasolla F, Department of Neurosciences, University of Bari, Italy, E-mail: f.stasolla@psico.uniba.it
}

Rec date: April 15, 2016; Acc date: April 22, 2016; Pub date: April 29, 2016

Copyright: ( 2016 Stasolla F, et al. This is an open-access article distributed under the terms of the Creative Commons Attribution License, which permits unrestricted use, distribution, and reproduction in any medium, provided the original author and source are credited.

Post-coma children usually fail to be constructively engaged with their surrounding environment, due to extensive motor disabilities and lack of speech. In fact, they may pose serious challenges to daily life contexts (i.e., home, medical and rehabilitative settings), since they are frequently unable to correctly manage the positive stimulation by their-own and they are inadequate to be involved within conventional and traditional programs [1,2]. Thus, these children may be not capable of: (a) regulate the amount and the type of stimulation available, and (b) positively interact or communicate with their partners (e.g., parents and caregivers), with negative outcomes on their quality of life $[3,4]$. To overcome this issue one may resort on assistive technology-based interventions (AT) [5]. AT refers to any device, equipment or piece enabling a participant affected by severe to profound developmental disabilities with self-determination towards the outside stimuli [6].

Depending upon their levels of vigilance and consciousness, one may envisage different rehabilitative programs. For instance, for children in a vegetative state (i.e., vigilance without consciousness), one may apply a basic AT intervention with an electronic tool such as a microswitch (i.e., sensor ensuring a child with severe to profound multiple disabilities with pleasant stimulation contingent to participant's behavioral response recording). That is, a single, a double or even a prolonged eye blinking may provide the child with brief periods (e.g., 7-10 seconds) of positive stimulation (e.g., a preferred song). By implementing an $\mathrm{ABABCBCB}$ experimental sequence (i.e., $\mathrm{A}$ representing baselines, $B$ indicating contingent intervention and $C$ the non-contingent control phase), one may assess the participant level of consciousness remaining.

Whenever the adaptive responding varying according to the aforementioned experimental phases, one may argue on participant favorable diagnosis of minimally conscious state [7]. For individuals in a minimally conscious state, one may adopt vocal output communication aid (VOCA) issues, aimed at requesting social contact with one or more caregivers [8]. Furthermore, computer-based programs focused on providing the participants with communication of their needs and/or occupation and leisure opportunities through different options hierarchically presented and automatically scanned by the system may be outlined [9]. Moreover, special message and phone calls systems with distant partners may be pointed out as to prevent apathy, isolation and passivity by post-coma participants [10]. Finally, for children who emerged from a minimally conscious state or are emerging from it, one may argue on the possibility of literacy access [11]. For all the aforementioned intervention, indices of positive participation (e.g., smiling, gaze oriented) may be carried out as outcome measures of quality of life as well as social validation assessment involving expert external raters for corroborating the clinical validity $[12,13]$.

In light of the above, new research within this framework is warranted to generalize the encouraging results and to individualize the technological solutions adopted focused on responding to the sophisticated demands of both the participants and their families. Moreover, the AT based interventions should be developed keeping in mind both human and financial resources available in daily contexts [14]. Accordingly, future perspective in this research area should deal with the following topics: (a) enlarging the number of participants involved, (b) the AT-based options rigorously customer-tailored to the users, (c) conducting new social validation assessment with new groups of experts involved, and (d) providing preference checks phases for participants who emerged or are emerging from minimally conscious states [15].

\section{References}

1. Cimolin V, Beretta E, Piccinini L, Turconi AC, Locatelli F, et al. (2012) Constraint-induced movement therapy for children with hemiplegia after traumatic brain injury: A quantitative study. J Head Trauma Rehabil 27: 177-87.

2. Eilander HJ, Van Heugten CM, Wijnen VJM, Croon MA, De Kort PLM, et al. (2013) Course of recovery and prediction of outcome in young patients in a prolonged vegetative or minimally conscious state after severe brain injury: An exploratory study. J Pediatr Rehabit Med 6: 73-83.

3. Dematteo CA, Hanna SE, Yousefi-Nooraie R, Lin C-A, Mahoney WJ, et al. (2014) Quality-of-life after brain injury in childhood: Time, not severity, is the significant factor. Brain Inj 28: 114-121.

4. Ilmer EC, Lambregts SAM, Berger MAM, De Kloet AJ, Hilberink SR, et al. (2016) Health-related quality of life in children and youth with acquired brain injury: Two years after injury. Eur J Paediatr Neurol 20: 131-139.

5. Lancioni GE, Singh NN (2014) Assistive technologies for people with diverse abilities. New York: Springer.

6. Lancioni GE, Sigafoos J, O'Reilly MF, Singh NN (2012) Assistive Technology. Interventions for Individuals with Severe/Profound and Multiple Disabilities. New York: Springer.

7. Lancioni GE, Bosco A, Belardinelli MO, Singh NN, O'Reilly MF, et al. (2014) Technology-based intervention programs to promote stimulation control and communication in post-coma persons with different levels of disability. Frontiers in Human Neuroscience 8.

8. Lancioni GE, O'Reilly MF, Singh NN, Buonocunto F, Sacco V, et al. (2009) Technology-based intervention options for post-coma persons with minimally conscious state and pervasive motor disabilities. Dev Neurorehabilitation 12: 24-31. 
Citation: Stasolla F, Boccasini A, Albano A, Albano V (2016) Assistive Technology-based Programs for Promoting Independence of Post-coma Children. Int J Neurorehabilitation 3: e119. doi:10.4172/2376-0281.1000e119

Page 2 of 2

9. Stasolla F, De Pace C (2014) Assistive technology to promote leisure and constructive engagement by two boys emerged from a minimal conscious state. NeuroRehabilitation 35: 253-259.

10. Lancioni GE, Singh NN, O'Reilly MF, Sigafoos J, Buonocunto F, et al. (2013) Technology-aided recreation and communication opportunities for post-coma persons affected by lack of speech and extensive motor impairment. Res Dev Disabil 34: 2959-2966.

11. Stasolla F, Caffò AO, Damiani R, Perilli V, Di Leone A (2015) Assistive technology-based programs to promote communication and leisure activities by three children emerged from a minimal conscious state. Cogn Process 16: 69-78.

12. Lancioni GE, Singh NN, O'Reilly MF, Sigafoos J, D'Amico F, et al. (2015) Assistive technology to help persons in a minimally conscious state develop responding and stimulation control: Performance assessment and social rating. NeuroRehabilitation 37: 393-403.

13. Levack WMM, Boland P, Taylor WJ, Siegert RJ, Kayes NM, et al. (2014) Establishing a person-centred framework of self-identity after traumatic brain injury: A grounded theory study to inform measure development. BMJ Open 4: e004630.

14. Stasolla F, Boccasini A (2016) Microswitch-based programs for post-coma patients with acquired brain injuries. Int J Behav Res Psychol 4: 1-2.

15. Lancioni GE, Singh NN, O'Reilly MF, Sigafoos J, Belardinelli MO, et al. (2014) Technology-aided programs for post-coma patients emerged from or in a minimally conscious state. Front Human Neurosci 8. 